\title{
Модификация терагерцового электромагнитного отклика полупроводникового полимера полифлуорена частицами оксида графена
}

\author{
(C) А.В. Андрианов, А.Н. Алешин
}

Физико-технический институт им. А.Ф. Иоффре РАН, Санкт-Петербург E-mail: alex.andrianov@mail.ioffe.ru; aleshin@transport.ioffe.ru

Поступило в Редакцию 20 июня 2016 г.

Методом терагерцовой спектроскопии во временной области исследован терагерцовый электромагнитный отклик композитных пленок на основе полупроводникового полимера полифлуорена и частиц оксида графена. Были измерены спектры комплексной диэлектрической проницаемости в спектральном диапазоне $0.3-2.8 \mathrm{THz}$ для композитных пленок полифлуорена с содержанием оксида графена 7, 26, 50.6 и 73 wt \%. Обнаружено значительное увеличение коэффициента терагерцового поглощения и действительной части проводимости композита полифлуорен - частицы оксида графена с ростом содержания частиц оксида графена в композите.

В последние годы наблюдается значительный рост активности в исследовании свойств графена и композитных материалов на основе графена в терагерцовой $(\mathrm{THz})$ области спектра, что обусловливается перспективами применения таких материалов в приборах высокоскоростной электроники и телекоммуникационных технологиях [1-4]. Бурно развивается также новый метод изучения конденсированных сред с использованием THz-спектроскопии во временной области (THz-TDS [5]). THz-TDS-методика позволяет проводить высокоточные измерения комплексной диэлектрической проницаемости исследуемого материала, что дает возможность бесконтактно изучать проводимость различных структур и частотную зависимость проводимости в THz-области спектра. Результаты THz-TDS-исследований важны для понимания механизма проводимости в таких сложных системах, как органические полупроводники [6,7] и биополимеры $[8,9]$. Недавно методами THz-спектроскопии во временной области был выполнен ряд 
исследований свойств графена (см., например, [10-12]), а также оксида графена $($ ОГ) $[13,14]$. В ряде работ сообщалось о значительных изменениях в диэлектрических и радиопоглощающих свойствах различных композитных материалов в СВЧ-области после введения в них модифицированных углеродных нанотрубок, графенов и оксида графена [15-17]. Оксид графена, обладающий относительно высокой проводимостью, также представляет интерес для применения в электронных приборах.

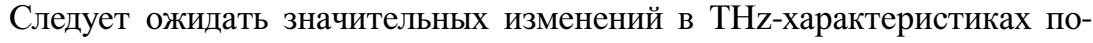
лимерных композитных систем после введения в них частиц ОГ.

В настоящей работе исследованы электрические и оптические свойства в THz-области спектра композитного материала на основе полупроводникового полимера полифлуорена Poly[9,9-bis-(2-ethylhexyl)9H-fluorene-2,7-diyl] (PFO), модифицированного добавлением частиц ОГ в различных соотношениях. Свойства матрицы композита - полимеpa PFO в THz-области были ранее исследованы нами в работе [6].

Исследовалось пропускание THz-излучения в области $0.3-2.8 \mathrm{THz}$ в пленках композита на основе полимера PFO с частицами ОГ, нанесенных на подложку (111) $p$-Si c удельным сопротивлением $10 \Omega \cdot \mathrm{cm}$ и толщиной $450 \mu \mathrm{m}$. Структуры молекул полимера PFO и частиц ОГ [18] приведены на рис. $1, a, b$. Полимер PFO, приобретенный в компании Sigma-Aldrich, растворялся в хлороформе с последующим ультразвуковым перемешиванием в течение $10 \mathrm{~min}$, затем в раствор добавлялись частицы ОГ, диаметр которых составлял $\sim 400-500 \mathrm{~nm}$, а число одноатомных слоев - от 2 до 10, приобретенные в $\mathrm{OOО}$ АкКоЛаб (Москва). Полученный композит наносился на кремниевую подложку методом drop-cast при $300 \mathrm{~K}$ и затем высушивался при $60-70^{\circ} \mathrm{C}$ в течение $30 \mathrm{~min}$ в атмосфере азота. Толщина полученных на кремнии пленок композита PFO - частицы ОГ по данным атомносиловой микроскопии составляла порядка $1 \mu \mathrm{m}$. Были получены пленки композита $\mathrm{PFO} /$ частицы ОГ, содержащие 7, 26, 50.6 и 73 весовых процентов (wt \%) ОГ.

THz-исследования проводились на установке когерентной THz-спектроскопии (или THz-TDS), созданной на основе фемтосекундного титан/сапфирового лазера с длиной волны $798 \mathrm{~nm}$, длительностью импульca 15 fs и энергией в импульсе 2.5 nanojoules $(\mathrm{nJ})$ [6]. Генерация THz-излучения достигалась при возбуждении пластинки $n$-InAs лазерными импульсами. THz-излучение детектировалось методом электрооптического стробирования THz волновых форм в кристалле $\mathrm{ZnTe}$ ориентации (110)

Письма в ЖТФ, 2016, том 42, вып. 22 


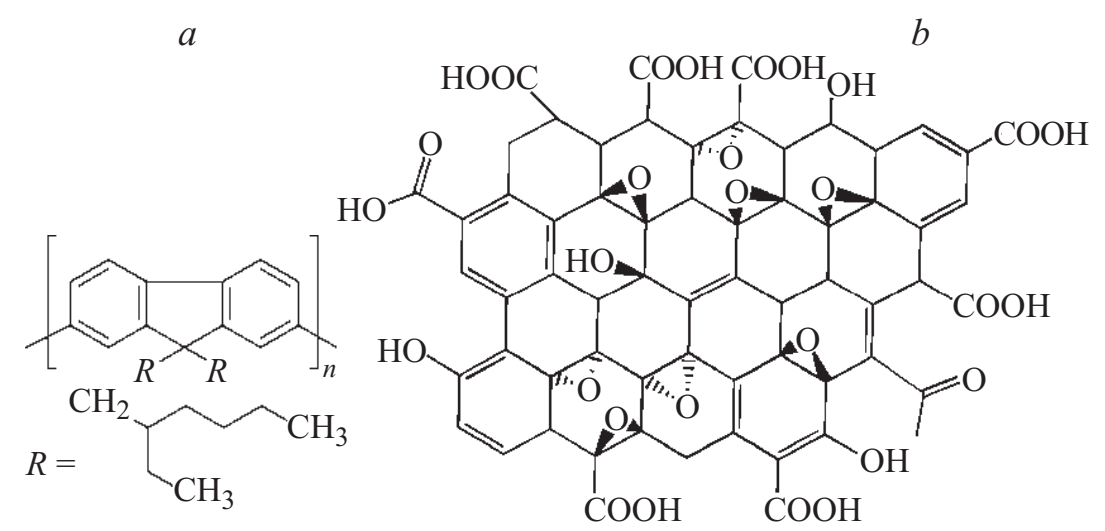

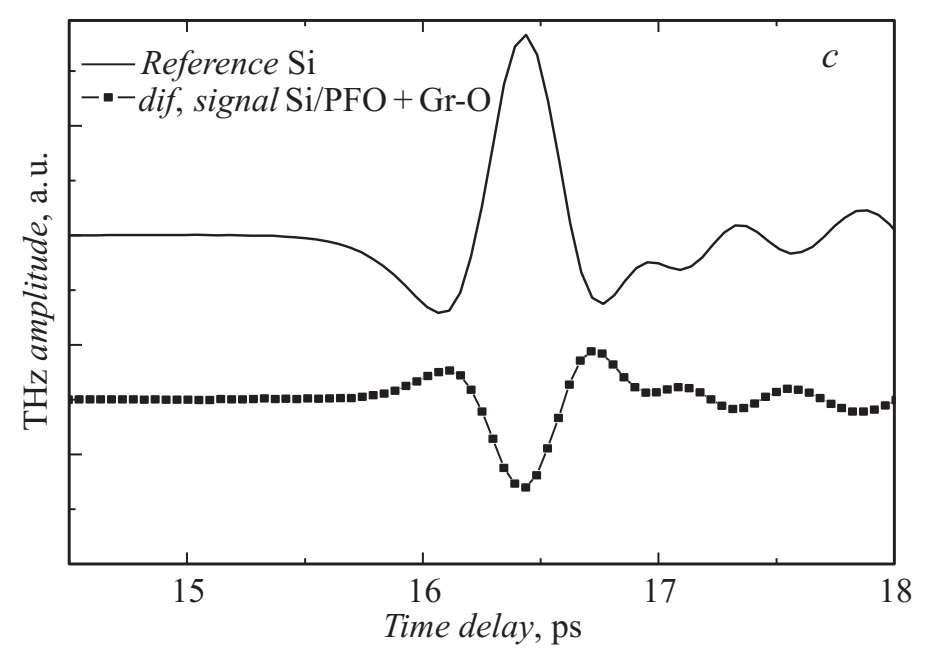

Рис. 1. $a-$ структура молекул полимера PFO $\left(E_{g} \sim 3.7 \mathrm{eV}\right) ; b-$ оксида графена [18]; $c$ - характерные волновые формы THz-сигналов: сигнал, прошедший через опорный образец (чистая подложка $\mathrm{Si}$ ), и сигнал дифференциального

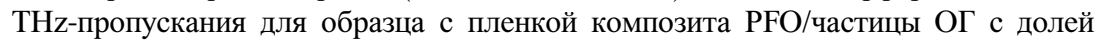
частиц ОГ $50.6 \mathrm{wt} \%$.

и толщиной $1 \mathrm{~mm}$. Спектральный диапазон $0.3-2.8 \mathrm{THz}$ определяется компонентами, входящими в состав когерентного THz-спектрометра 
(главным образом детектором излучения на основе кристалла ZnTe), которые обеспечивают достаточно высокое соотношение сигнал/шум (по амплитуде сигнала порядка $10^{4}$ без исследуемого образца) только в диапазоне $0.3-2.8 \mathrm{THz}$. Спектральное разрешение в большинстве измерений составляло $0.1 \mathrm{THz}$. Измерения проводились при комнатной температуре на открытом воздухе при влажности 56\%. В данной работе

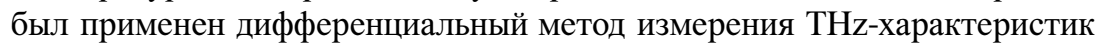
тонких пленок, детально описанный в [6]. Данная методика позволяет непосредственно получить частотную зависимость комплексной диэлектрической проницаемости материала пленки из спектра комплексного коэффициента дифференциального пропускания исследуемого образца (разностного по отношению к опорному образцу без исследуемой пленки).

На рис. 1, с приведены характерные волновые формы $\mathrm{THz}$ опорного сигнала, прошедшего через кремниевую подложку, и дифференциального THz-сигнала, представляющего собой разность сигнала, прошедшего через образец с пленкой исследуемого композита $\mathrm{PFO/частицы} \mathrm{ОГ,} \mathrm{и}$ опорного сигнала. Форма дифференциального THz-сигнала отражает ослабление THz-импульса за счет поглощения в пленке композита и небольшую временную задержку THz-импульса в пленке. Фурьепреобразование опорного и дифференциального ТHz-сигналов позволяет получить комплексный коэффициент дифференциального пропускания исследуемой пленки, $T(\omega)=\frac{E_{\text {diff }}(\omega)}{E_{\text {ref }}(\omega)}$, где $E_{\text {diff }}(\omega)$ и $E_{\text {ref }}(\omega)-$ комплексные амплитуды дифференциального и опорного THz-сигналов соответственно. Коэффициент $T(\omega)$ для тонкой пленки может быть представлен в виде

$$
T(\omega)=i \frac{\omega d}{c\left(n_{s}+1\right)}\left(\varepsilon_{f}^{\prime}-1+i \varepsilon_{f}^{\prime \prime}\right),
$$

где $\omega=2 \pi f ; f-$ частота; $d-$ толщина пленки; $c-$ скорость света; $n_{s}$ - показатель преломления кремниевой подложки, который можно принять равным 3.4 в данном спектральном диапазоне; $\varepsilon_{f}^{\prime}$ и $\varepsilon_{f}^{\prime \prime}$ - действительная и мнимая часть диэлектрической проницаемости материала пленки соответственно.

Из спектра комплексной диэлектрической проницаемости материала пленок определялись спектры коэффициента THz-поглощения и действительной проводимости исследуемого материала с использованием

Письма в ЖТФ, 2016, том 42, вып. 22 

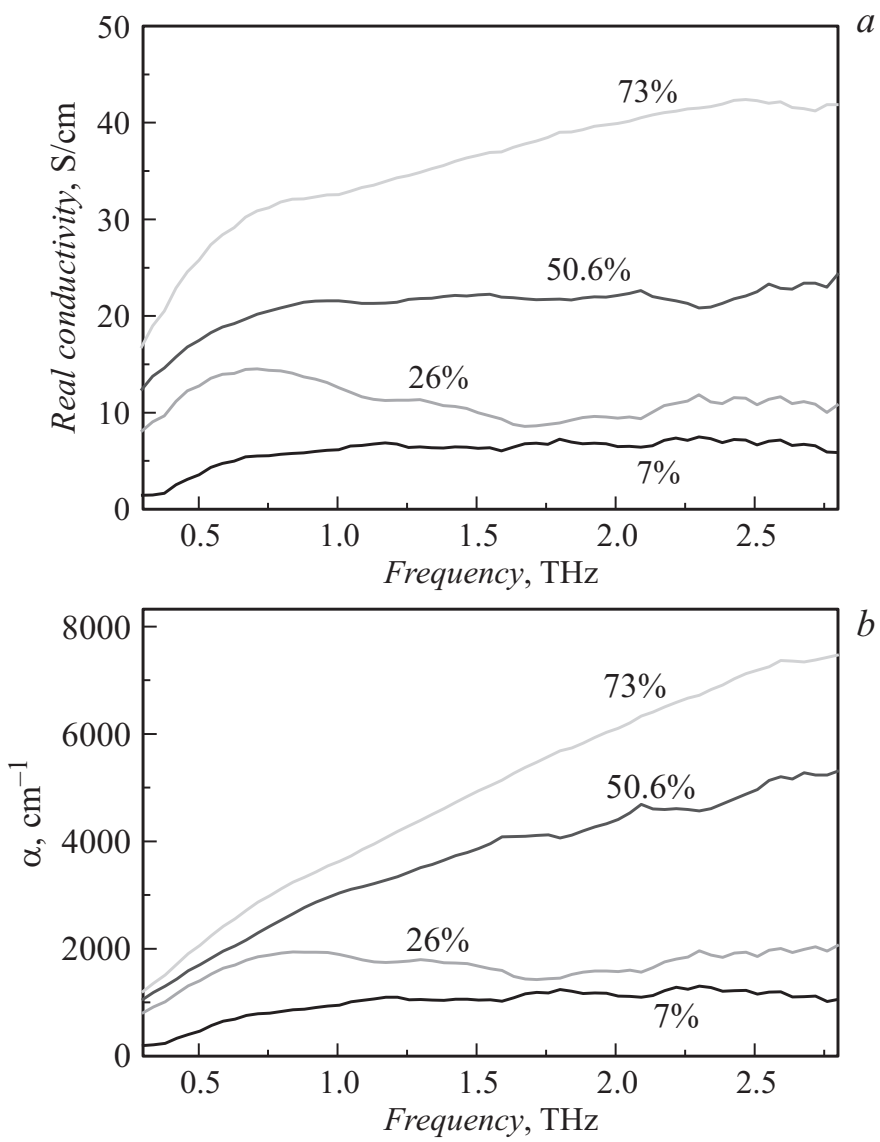

Рис. 2. $a-$ частотная зависимость действительной части проводимости композита $\mathrm{PFO/частицы} \mathrm{ОГ} \mathrm{с} \mathrm{различным} \mathrm{содержанием} \mathrm{частиц} \mathrm{ОГ:} \mathrm{7,} \mathrm{26,}$ 50.6, $73 \mathrm{wt} \% ; b$ - спектры коэффициента THz-поглощения по мощности композита PFO/частицы ОГ с различным содержанием частиц ОГ: 7, 26, 50.6, $73 \mathrm{wt} \%$.

известных соотношений [19]. Такая процедура измерений и расчетов была проведена для набора пленок композита $\mathrm{PFO/частицы} \mathrm{ОГ} \mathrm{с}$ весовыми долями ОГ 7, 26, 50.6 и $73 \mathrm{wt} \%$.

Письма в ЖТФ, 2016, том 42, вып. 22 


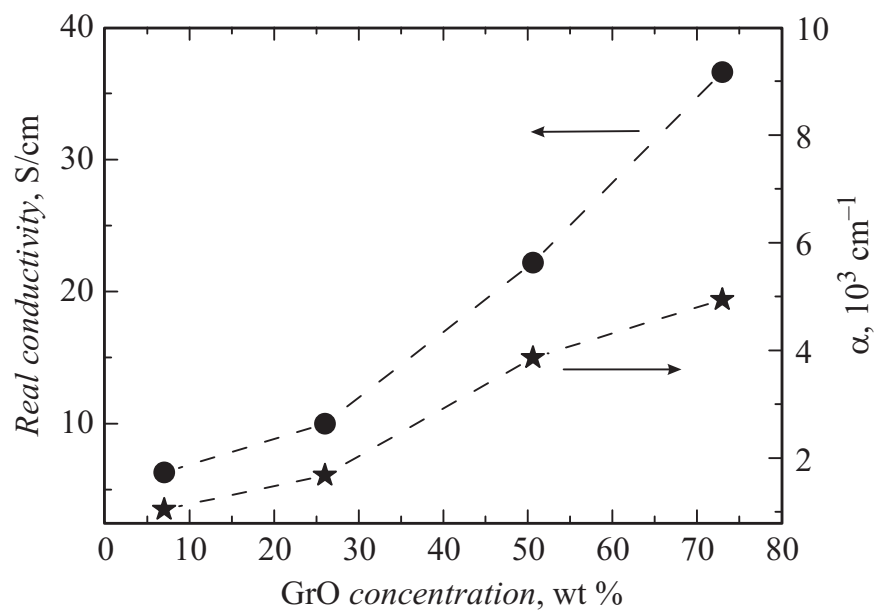

Pис. 3. Зависимости действительной части проводимости и коэффициента THz-поглощения по мощности композита PFO/частицы ОГ при $1.5 \mathrm{THz}$ от содержания частиц ОГ.

На рис. 2, $a$ приведены полученные частотные зависимости проводимости исследованного композита $\mathrm{PFO} /$ частицы ОГ с различным содержанием частиц ОГ. Как видно из рис. 2, $a$, проводимость композита существенно возрастает с ростом содержания частиц ОГ. Важно добавить, что частотная зависимость проводимости плавная и имеет тенденцию к насыщению при возрастании частоты, что свойственно проводимости металлического типа. Такое поведение проводимости композита $\mathrm{PFO/частицы} \mathrm{ОГ} \mathrm{заметно} \mathrm{отличается} \mathrm{от} \mathrm{характера} \mathrm{прово-}$ димости, наблюдаемой в чистом полимере $\mathrm{PFO}$, в котором частотная зависимость проводимости была монотонной и близкой к степенной с показателем степени порядка 1.7-1.8 [6].

На рис. $2, b$ приведены спектры коэффициента THz-поглощения по мощности для композита $\mathrm{PFO} /$ частицы ОГ с различным содержанием частиц ОГ. Видно, что величина коэффициента поглощения также значительно возрастает при возрастании содержания частиц ОГ в композите от 7 до 26, 50.6 и $73 \mathrm{wt} \%$ и на границе исследованного спектрального диапазона коэффициент превышает величину $7400 \mathrm{~cm}^{-1}$ для композита, содержащего $73 \mathrm{wt} \%$ частиц ОГ.

Письма в ЖТФ, 2016, том 42, вып. 22 
Зависимости действительной части проводимости и коэффициента THz-поглощения в композите $\mathrm{PFO} /$ частицы ОГ от содержания частиц ОГ для средней частоты исследованного спектрального диапазона $(1.5 \mathrm{THz})$ приведены на рис. 3 . Как видно из рис. 3 (а также из рис. $2, a, b)$, наблюдается значительное увеличение коэффициента $\mathrm{THz}$-поглощения и действительной части проводимости композитных пленок $\mathrm{PFO/частицы} \mathrm{ОГ} \mathrm{с} \mathrm{ростом} \mathrm{содержания} \mathrm{частиц} \mathrm{ОГ} \mathrm{в} \mathrm{композите,}$ а также по сравнению с исходными немодифицированными пленками PFO [6]. Таким образом, введением частиц оксида графена в полимер PFO можно эффективно модифицировать THz-электромагнитный отклик данного композитного материала.

В работе исследован THz-электромагнитный отклик композитных пленок на основе полупроводникового полимера PFO и частиц ОГ в спектральном диапазоне $0.3-2.8 \mathrm{THz}$. Для композитных пленок PFO с содержанием ОГ 7, 26, 50.6 и $73 \mathrm{wt} \%$ обнаружено значительное увеличение коэффициента THz-поглощения и действительной части проводимости композита $\mathrm{PFO} /$ частицы ОГ с ростом содержания частиц ОГ. Полученные результаты показывают, что введение частиц ОГ в матрицу полупроводникового полимера PFO является эффективным способом модификации его электрических и оптических свойств в THz-области спектра.

Работа выполнена при частичной поддержке программ президиума РАН: „Фундаментальные и прикладные проблемы фотоники и физика новых оптических материалов“ и П8 „Полифункциональные вещества и материалы для молекулярной электроники“, а также гранта СПбГУ 11.38.219.2014.

\section{Список литературы}

[1] Bonaccorso F., Sun Z., Hasan T. et al. // Nat. Photonics. 2010. V. 4. P. 611-622.

[2] Han S.J., Jenkis K.A., Valdes Garcia A. et al. // Nano Lett. 2011. V. 11. P. 36903693.

[3] Wu Y., Lim Y.M., Bol A.A. et al. // Nature. 2012. V. 472. P. 74-78.

[4] Maeng I., Lim S., Chae S.J. et al. // Nano Lett. 2012. V. 12. P. 551-555.

[5] Ferguson B., Zhang X.-C. // Nature Materials. 2002. V. 1. P. 26-33.

[6] Andrianov A.V., Aleshin A.N., Truhin V.N. et al. // J. Phys. D: Appl. Phys. 2011. V. 44. P. $265101(6$ pp.). 
[7] Gusakov P.E., Andrianov A.V., Aleshin A.N. et al. // Synth. Metals. 2012. V. 162. P. $1846-1851$.

[8] Aleshin A.N., Berestennikov A.S., Krylov P.S. et al. // Synth. Metals. 2015. V. 199. P. $147-151$.

[9] Andrianov A.V., Aleshin A.N., Khripunov A.K. et al. // Synth. Metals. 2015. V. 205. P. 201-205.

[10] George P.A., Strait J., Dawlaty J. et al. // Nano Lett. 2008. V. 8. P. 4248-4251.

[11] Tomaino J.L., Jameson A.D., Kevek J.W. et al. // Opt. Express. V. 19. P. 141-146.

[12] Ren L., Zhang Q., Yao J. et al. // Nano Lett. 2012. V. 12. P. 3711-3715.

[13] Jung G.B., Myung Y., Cho Y.J. et al. // J. Phys. Chem. C. 2010. V. 114. P. $11258-$ 11265.

[14] Hong J.T., Lee K.M., Son B.H. et al. // Opt. Express. 2013. V. 21. P. 7633-7640.

[15] Hashishoa Z., Rood M.J., Barot S. et al. // Carbon. 2009. V. 47. P. 1814-1823.

[16] Tung T.T., Feller J.-F., Kim T.Y. et al. // J. Polymer Sci. A. 2012. V. 50. P. 927935.

[17] Мурадян В.E., Арбузов А.А., Соколов Е.А. и др. // Письма в ЖТФ. 2013. T. 39. B. 18. C. 1-7.

[18] He H., Klinowski J., Forster M. et al. // Chem. Phys. Lett. 1998. V. 287. P. 53-56.

[19] Born M., Wolf E. Principles of Optics. Oxford: Pergamon, 1987. P. 441. 